\title{
The Moral Aspect of Nonmoral Goods and Evils
}

\author{
MICHAEL J. ZIMMERMAN \\ University of North Carolina at Greensboro
}

\begin{abstract}
The idea that immoral behaviour can sometimes be admirable, and that moral behaviour can sometimes be less than admirable, has led several of its supporters to infer that moral considerations are not always overriding, contrary to what has been traditionally maintained. In this paper I shall challenge this inference. My purpose in doing so is to expose and acknowledge something that has been inadequately appreciated, namely, the moral aspect of nonmoral goods and evils. I hope thereby to show that, even if immorality can be admirable (and morality less than admirable), this poses no threat to morality.
\end{abstract}

The idea that immoral behaviour can sometimes be admirable, and that moral behaviour can sometimes be less than admirable, has recently received a good deal of attention. Some have supported this idea, others have rejected it. The idea has led several of its supporters to infer that moral considerations are not always overriding, contrary to what has been traditionally maintained. In this paper I shall challenge this inference. My purpose in doing so is not to salvage either the claim that immorality can be admirable (and morality less than admirable) or the claim that moral considerations are always overriding. On the contrary, I am unsure about the former and have serious reservations about the latter, for reasons that I shall try to make clear. My purpose, rather, is to expose and acknowledge something that has been inadequately appreciated, namely, the moral aspect of nonmoral goods and evils. In so doing I hope to show that, even if immorality can be admirable (and morality less than admirable), this poses no threat to morality. There is no paradox lurking here, nor is morality to be relegated to a position that is somehow inferior to that which it is traditionally thought to occupy.

\section{WHAT ADMIRABLE IMMORALITY AND NONADMIRABLE MORALITY ARE (OR ARE SUPPOSED TO BE)}

There are many illustrations in the recent literature of behaviour that is alleged to be at once both admirable and immoral. Probably the bestknown and -worn illustration is that provided by Bernard Williams of Gauguin, who abandoned his family in his pursuit of artistic excellence. ${ }^{1}$ Susan Wolf has presented a variety of cases in a similar vein,

${ }^{1}$ Bernard Williams, Moral Luck, Cambridge, 1981, pp. $22 \mathrm{ff}$. 
where people engage in artistic or otherwise creative endeavours at the expense of seeing to the welfare of others who are in need. ${ }^{2}$ Michael Slote has also presented both cases of this sort and cases where the devotion in question is directed to other types of goals, such as seeing to the needs of one's family or one's country, but still at the expense of, rather than in the service of, doing what is morally right. ${ }^{3}$ And others have discussed yet other cases.

Illustrations similarly abound of behaviour that is alleged to be at once both moral and nonadmirable (perhaps even regrettable or reprehensible). ${ }^{4}$ Michael Stocker has provided the case of someone who visits an acquaintance in hospital not so much out of friendship as out of a sense of duty. ${ }^{5}$ Similarly, Williams has noted that a wife in peril may well hope that her husband rescues her simply because she is his wife, and not (also) because it is morally permissible for him to do so. ${ }^{6}$ Wolf has discussed at length the deficiencies of persons whom she calls 'moral saints' - persons 'whose every action is as morally good as possible' and whose lives are, as a result, 'strangely barren'. ${ }^{7}$ And, again, others have discussed yet other cases.

In all cases of the sorts just mentioned there is allegedly a divergence of the admirable and the moral. But precisely what sort of divergence is at issue? Slote has drawn a much-discussed distinction between three theses concerning admirable immorality. ${ }^{8}$ He calls the first of these the strong thesis, and it can be rendered as follows:

(ST) Immoral behaviour as such is sometimes admirable.

The second he calls the weak thesis, and it can be rendered as follows:

(WT) Certain aspects of immoral actions are sometimes admirable, and certain traits of persons that make them more likely to act wrongly are sometimes admirable.

In presenting (ST) and (WT) in this way, I have followed closely Slote's own rendition of them. He is not so explicit when it comes to the third thesis, which he calls the intermediate thesis, but it is fairly clear that the following is what he has in mind:

${ }^{2}$ Susan Wolf, 'Moral Saints', Journal of Philosophy, lxxix (1982), $420 \mathrm{ff}$.

${ }^{3}$ Michael Slote, Goods and Virtues, Oxford, 1983, pp. $80 \mathrm{ff}$.

'I prefer the terms 'regrettable' and 'reprehensible' to the term 'repugnant', which is sometimes used in this context. The suffixes '-able' and '-ible' indicate that what is at issue is the worthiness of a certain attitude, whether or not that attitude is in fact taken by anyone.

${ }^{5}$ Michael Stocker, 'The Schizophrenia of Modern Ethical Theories', Journal of Philosophy, lxxiii (1976), 462.

${ }^{6}$ Williams, p. 18.

${ }^{7}$ Wolf, 419 and 421.

${ }^{8}$ Slote, p. 79. 
(IT) Certain aspects of immoral actions that are intrinsically connected with their immorality are sometimes admirable, and certain traits of persons that are intrinsically connected with making them more likely to act wrongly are sometimes admirable.

Instead of the term 'are intrinsically connected with', Slote occasionally uses the terms 'cannot be conceptually prised from' and 'are not merely externally related to'. ${ }^{9}$

It is on the intermediate thesis that Slote and his commentators have tended to focus. This is because they regard the strong thesis as rather obviously false and the weak thesis as rather obviously true. $^{10}$ The strong thesis would appeal, Slote says, only to those of a Nietzschean bent, who regard morality as either pathological or degenerate. The weak thesis, on the other hand, is continually confirmed in everyday life, as when a bank robbery is executed with daring or, perhaps, a safe is cracked with skill. But it seems to me that this move to the middle is premature, for as they stand none of the three theses is especially clear.

First, the use of 'sometimes' is puzzling. It suggests 'sometimes and only sometimes'. But how, for example, could immoral behaviour as such be sometimes but only sometimes admirable? Or how could a certain trait (as such, that is, in and of itself) be sometimes but only sometimes admirable? It might of course be that a trait when manifested in certain circumstances $C$ is admirable, whereas when manifested in certain other circumstances $C^{\prime}$ it is not. But this would not imply that the trait in and of itself is sometimes admirable and sometimes not. On the contrary, the explanation must be either that the trait is admirable in and of itself, but its admirability is somehow overridden (whether simply counterbalanced or otherwise defeated) by other features of circumstances C' (though not overridden by any features of circumstances $\mathrm{C}$ ); or that the trait is not admirable in and of itself, but the trait-cum-C is (although the trait-cum-C' is not). ${ }^{11} \mathrm{I}$ propose that henceforth we eschew such talk of 'sometimes'.

Secondly, both 'aspects' of actions and traits of persons are said to be such that they may be admirable. But what sort of aspects are at issue? The example of a daring robbery suggests that the aspect in question is simply the manifestation of a certain personal trait. After

${ }^{9}$ Ibid., pp. 84,79 and 80 respectively.

${ }^{10}$ See, e.g., Slote, p. 79; Owen Flanagan, 'Admirable Immorality and Admirable Imperfection', Journal of Philosophy, lxxxiii (1986), 42.

${ }^{11}$ In putting matters thus, I am opposing the sort of particularism espoused by Jonathan Dancy in Moral Reasons, Oxford, 1993. There is no space to elaborate on this here. 
all, it is robbers who dare, not robberies. I propose, therefore, that we focus on (allegedly) admirable traits of persons. (There is, of course, a distinction between the possession and the manifestation of a trait, and each might be said to be admirable in its own right. I hope it is acceptable to ignore this subtlety here. I shall be focusing on cases where traits are manifested in action but shall leave unsettled whether it is the mere possession of the traits or their manifestation whose admirability is in question.)

Thirdly, the strong thesis mentions 'behaviour' whereas the others mention 'actions'. Sometimes the latter term is construed more narrowly than the former, but I think that in this context it ought not to be.

Finally, there is talk of actions' being 'immoral' and of their being 'wrong'. On some views, actions are properly called immoral only if they stem from some morally bad motive (or otherwise manifest some morally bad trait) and hence are themselves morally bad, whereas actions can be wrong even when well motivated and hence morally good. Presumably some motivational deficiency is at issue in the three theses. They do not concern actions that 'just happen' to be wrong (if this is possible); they concern actions that are morally bad, actions that reflect ill on the agent. This, of course, is the source of the alleged tension. How can it be that an agent's actions both manifest an admirable trait and yet reflect ill on him or her?

I propose, therefore, that we concern ourselves with the following theses:

(ST1) The moral badness of morally bad actions is admirable in and of itself.

(WT1) Certain traits that are sometimes manifested in morally bad actions are admirable in and of themselves.

(IT1) Certain traits that are sometimes manifested in morally bad actions and are intrinsically connected with their moral badness are admirable in and of themselves.

I think we should agree that (ST1) is false. But what about the others?

I would think that (WT1) is pretty clearly true, if the admixture of morally good with morally bad motives or traits is possible and is supposed to be covered by this thesis. If, for example, sympathy is a morally good motive and jealousy a morally bad one, and if it is possible that I perform some act both out of sympathy and out of jealousy, then my act may perhaps be properly said to be morally bad (especially if the jealousy in some sense predominates); yet the sympathy would seem to be admirable. But even if such admixture is not admitted, I would think that (WT1) is pretty clearly true. The example of a daring robbery would seem to suffice here. The robbery may be ill motivated, 
and hence morally bad, and yet the daring with which it is executed would seem admirable, even if not morally good. ${ }^{12}$

Whether (IT1) should be accepted depends on just what is meant by 'intrinsically connected with'. In her advocacy of unsaintly behaviour, Wolf stresses the fact that, the world being as it is, one cannot play the oboe or improve one's backhand while striving to do all that is within one's power to fight famine and disease. ${ }^{13}$ But this is presumably not sufficient for the sort of connection between admirability and (im)morality that Slote has in mind, since this incompatibility between admirable and morally good behaviour is merely practical rather than conceptual. Slote emphasizes devotion to a cause which precludes morally good behaviour because he is impressed by the 'single-mindedness' of such an attitude. It is not simply that, the world being as it is, such devotion precludes such behaviour; for we can imagine a more fortunate world in which the devotion and the behaviour are compatible. I take Slote's point to be that, even in a more fortunate world of this sort, genuine devotion to the sort of cause he has in mind essentially involves a preparedness to cast aside moral considerations, should circumstances so warrant. ${ }^{14}$ Such preparedness is a conceptual mark of the single-mindedness with which he is concerned. Once this is understood, though, I think it is not at all obvious that the intermediate thesis is true. This is an issue to which I shall return in section III.

Corresponding to the three theses concerning admirable immorality, the following three theses concerning nonadmirable morality may be distinguished:

(ST2) The moral goodness of morally good actions is nonadmirable in and of itself.

(WT2) Certain traits that are sometimes manifested in morally good actions are nonadmirable in and of themselves.

(IT2) Certain traits that are sometimes manifested in morally good actions and are intrinsically connected with their moral goodness are nonadmirable in and of themselves.

As with their counterparts, (ST2) seems clearly false and (WT2) pretty clearly true, while (IT2) may seem more problematic. We might wish to agree with Wolf that many nonmoral traits are admirable without agreeing that a devotion to duty must involve nonadmirable behaviour. Again, I shall return to this in section III below.

${ }^{12}$ Not everyone will agree with this claim, of course. One recent example of someone who would apparently reject it is Judith Jarvis Thomson in 'The Right and the Good', Journal of Philosophy, xciv (1997), 285.

${ }^{13}$ Wolf, 421.

${ }^{14}$ Compare the emphasis placed on the tendency to act immorally in Richard McCarty, 'Are There “Contra-Moral Virtues"?', Metaphilosophy, xxv (1994), $364 \mathrm{f}$. 


\section{PERSONAL VS. INTRINSIC VS. MORAL GOODS AND EVILS}

It is important to recognize that the good and bad traits involved in moral and immoral actions are of course morally good and bad, respectively, since there are other types of goods and evils. Two other types worth brief consideration are personal and intrinsic goods and evils.

Consider personal goods and evils. A man's sadistic pleasures may be properly said to be good-for-him, even if they are neither intrinsically nor morally good. As Slote observes:

[I]t would be senseless ... to argue that sadistic pleasures are not personal goods because no disinterested being would wish them to exist, because it is not intrinsically good that they should exist. A disinterested being might also disapprove of a vicious man's being happy, but it hardly follows that the vicious man is not well off. And we have no more reason on that score to deny that sadistic pleasures are personal goods. ${ }^{15}$

Consider a man who is devoted to the pursuit of his own sadistic pleasures. Acting accordingly, he manifests a trait that is both intrinsically connected with something that is personally good and is nonadmirable; but this clearly does not support (IT2), since that thesis concerns what is morally rather than personally good. Similarly, physical pain is a personal evil, but a preparedness to endure such pain for the sake of others, while admirable, does not support (IT1), since that thesis concerns what is morally rather than personally bad.

Intrinsic goods and evils are more closely connected to moral goods and evils than personal goods and evils are. But still there is a distinction to be drawn, for, while I suppose it to be true that all moral goods and evils are intrinsic goods and evils, respectively, the reverse is false. (This is an important point to which I shall return in section V.) Almost everyone will agree that physical pain (or, at least, undeserved physical pain) is intrinsically bad, but it is properly classified not as a moral evil but as something else (a 'natural' evil, perhaps). So too, many pleasures (of a certain restricted sort, perhaps) are plausibly regarded as intrinsically good, but not as morally good. This being the case, even if there is reason to think that certain analogues to (IT1) and (IT2) having to do with intrinsic value are true, this may not provide confirmation of (IT1) and (IT2) themselves. For example, devotion to the pursuit of one's own perfectly innocent pleasures does not support (IT2), nor does a preparedness to endure undeserved physical pain for the sake of others support (IT1). 


\section{ARE THE INTERMEDIATE THESES TRUE?}

In principle, any illustration that is offered as confirmation of (IT1) can be challenged in one of three ways. It may be claimed that the behaviour in question is not admirable, or that it is not immoral, or that its admirability is not intrinsically connected with its immorality. It is exactly such challenges that some of Slote's commentators have made. For example, Owen Flanagan has noted that many will find nothing admirable in Gauguin's behaviour (although they may be quite willing to declare artistic passion that is moderated by moral sensitivity admirable), that others will find nothing immoral in it, and that still others will deny the requisite intrinsic connection. ${ }^{16}$ Indeed, he himself pursues the third course,$^{17}$ as does Marcia Baron, who also pursues the first, arguing that which type of challenge applies to the case of Gauguin and other such cases depends on just how these cases are to be construed. ${ }^{18}$

Since it is hard to see how such challenges might be definitively settled, I think it must be agreed that the truth of (IT1) remains an open question. Similar remarks pertain to (IT2), which is in principle open to three analogous challenges, although there is this complication: nonadmirability can come in various forms. Note first that 'nonadmirable' might simply mean the same as 'not worthy of being admired', or it might mean the same as 'worthy of not being admired'. I think that, where nonadmirable morality has been diagnosed, it is typically the latter interpretation - at least - that has been intended. I say 'at least' because there are of course still stronger forms of nonadmirability. Something might be nonadmirable because it is regrettable, or even reprehensible. It is clear that some have found morally good behaviour on occasion regrettable. Wolf, for example, indicates this when she notes that a moral saint lacks, indeed must lack (thereby satisfying Slote's condition concerning intrinsic connectedness), a cynical or sarcastic wit. ${ }^{19}$ It is doubtful, though, that she would find the absence of such a wit reprehensible. (Other behaviour that may be exhibited by moral saints - such as their acting in a 'dull-witted or humorless or bland' manner ${ }^{20}$ - she would perhaps find reprehensible, but I do not think that she would insist that a moral saint must exhibit such behaviour.) ${ }^{21}$ The difference between 'regrettable' and 'reprehen-

${ }^{16}$ Flanagan, $43 \mathrm{f}$.

17 Ibid., 44 ff.

${ }^{18}$ Marcia Baron, 'On Admirable Immorality', Ethics, xcvi (1986), $563 \mathrm{ff}$.

19 Wolf, 422.

${ }^{20}$ Ibid.

${ }^{21}$ That moral saints need not exhibit such behaviour has recently been forcefully argued by Tracy Isaacs and Diane Jeske in 'Moral Deliberation, Nonmoral Ends, and the Virtuous Agent', Ethics, cvii (1997). 
sible' seems to be this: the mere absence of something good is arguably regrettable but not reprehensible; reprehension, to be warranted, requires the presence of something bad. ${ }^{22}$

There are, then, at least three versions of (IT2) that can be distinguished. First there is (IT2) as stated (with 'nonadmirable' understood in terms of 'worthy of not being admired'). Then there is a stronger version - call it (IT2+) - where 'nonadmirable' is replaced by 'regrettable'. Then there is a still stronger version - call it (IT2++) where 'nonadmirable' is replaced by 'reprehensible'. Once these versions are distinguished, I think it is clear that (IT2) itself is a fairly weak thesis and one that is pretty plausible. After all, even if devotion to duty is admirable, it is plausible to claim that it cannot be exhibited without something else's being exhibited that would seem worthy of indifference; for example, it cannot be exhibited without the agent's also exhibiting agency. (IT2++), on the other hand, is really quite strong, and it is not clear that anyone has sought to champion it. ${ }^{23}$ In between, of course, lies (IT2+), which clearly has been advocated by some and concerning which there are, I suspect, differences of opinion whose definitive resolution would appear as elusive as the resolution of those concerning (IT1).

\section{WHO NEEDS THE INTERMEDIATE THESES ANYWAY?}

I have been concerned with the intermediate theses (IT1) and (IT2) (and strengthened versions of the latter) because it is they in particular that have been invoked in the case that some have made against the claim that moral considerations are always overriding. The suggestion seems to be that the weak theses (WT1) and (WT2) are not strong enough to make this case. (Slote even says that (WT1) does not involve something that we would want to call 'admirable immorality' at all. $)^{24}$ But it seems to me that this emphasis on the intermediate theses is misplaced. If these theses give good reason to reject the overridingness thesis, then so too do the weak theses. And the truth of the weak theses is not in contention, even if that of the intermediate theses is.

My point is this. The simple fact that some nonmoral traits are admirable may seem to indicate the nonsupremacy of moral consider-

${ }^{22}$ See Wolf, 435 .

${ }^{23}$ This having been said, there is perhaps a reason for affirming (IT2++) that, as far as I know, has not been discussed by those who have been concerned with the possibility of nonadmirable morality. This reason has to do with resisting the temptation to do evil. Such resistance seems to be morally good, and yet it cannot occur in the absence of such temptation, which itself seems reprehensible.

${ }^{24}$ Slote, p. 79. 
ations. Slote suggests that Gauguin's immoral action, whose admirability is allegedly intrinsically connected with its immorality, is somehow preferable to his acting morally would have been, and that this shows the overridingness thesis false. But why should some of Wolf's cases not be thought to have equal force, even if the connection between admirable traits and immoral behaviour is in these cases found to be merely practically unavoidable rather than conceptually undeniable? Even if it is merely the world as it is that renders it impossible for someone to be both a moral saint and a gourmet cook, ${ }^{25}$ if it is nonetheless thought desirable that some people sometimes engage in such culinary pursuits rather than act morally, is this not enough to establish Wolf's claim that 'morality should not serve as a comprehensive guide to conduct'? ${ }^{26}$ So who needs the intermediate theses anyway?

At this point we need to inquire into the basic question as to how it is that nonmoral traits can be admirable.

\section{THE MORAL ASPECT OF NONMORAL GOODS AND EVILS}

It is a commonplace that there are both moral and nonmoral virtues (and vices). Frequently cited as moral virtues are such traits as compassion, courage, and conscientiousness, and as nonmoral virtues such traits as intelligence, wit, and aesthetic sensitivity. Whether moral or nonmoral, a virtue (or vice) is taken somehow to reflect well (or ill) on its possessor; just how it does this will of course depend on just what the trait in question is. And it is not just virtues (and vices) that reflect well (and ill) on their possessors. Only a courageous person, I suppose, can exhibit the virtue of courage; for virtues, whatever they are exactly, are traits that are relatively well entrenched and long-standing. ${ }^{27}$ But someone who is not a courageous person can nonetheless show courage on occasion, and such behaviour will still reflect well on him or her. Since this is so, let us say (although this perhaps stretches normal usage somewhat) that, even in the case of an uncharacteristic display of courage, the agent manifests the trait (even if not the virtue) of courage. Then our lists of moral and nonmoral virtues (and vices) can be treated as lists of moral and nonmoral traits generally that reflect well (and ill) on their possessors.

Now here is a central truth. Whenever a trait is displayed that reflects well (or ill) on its possessor, that trait is admirable (or repre-

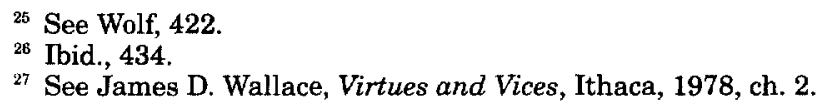


hensible) - and so is its agent (to that extent, at least, and on that occasion) - regardless of whether the trait is moral or nonmoral, and even if (if this is possible) the trait has some sort of intrinsic connection with morally bad (or good) behaviour. It is of course precisely this fact that some have seen to pose some sort of threat to morality.

To say that a trait is admirable (or reprehensible) is to say that it is worthy of admiration (or reprehension), that it is fitting or appropriate to admire (or reprehend) it. This notion of fittingness has an impressive pedigree. It played a large role in the moral theories of several eighteenth-century British philosophers ${ }^{28}$ and has since been resurrected by, among others, Franz Brentano and Roderick Chisholm, although the former tends to talk of the 'correctness' of certain attitudes while the latter tends to talk of certain attitudes being 'required' ${ }^{29}$ Fittingness is a relation that is not restricted to attitudes and their objects; its extension is much wider. As illustrations of one thing requiring another, Chisholm gives the following: '... promise-making requires - or calls for - promise-keeping; being virtuous requires ... being rewarded; the dominant seventh requires the chord of the tonic; one color in the lower left calls for a complementary color in the upper right'. ${ }^{30}$

Here, though, we should draw a distinction that Chisholm fails to draw (although others have drawn it ${ }^{31}$ ), and that is between ethical or moral requirement and other types of requirement. If promise-making requires promise-keeping, this is a moral matter, whereas, if one colour calls for another that is complementary rather than incongruous, that is a matter of aesthetics. ${ }^{32}$ It is, after all, unlikely that promise-making calls aesthetically for promise-keeping, or that one colour calls morally for another - unlikely, but possible, and this possibility underscores rather than undermines the distinction in question. Consider promise-making and -keeping. If the former morally requires the latter, this is presumably a direct requirement; that is, it is a requirement that is not itself attributable to any other moral requirement. ${ }^{33}$ Suppose, however, that I have promised to put one colour in the

${ }^{28}$ Such as John Balguy, John Brown, Samuel Clarke, Richard Price and Adam Smith. See the selections of their and others' works edited in two volumes by L. A. Selby-Bigge in British Moralists, Oxford, 1897.

${ }^{29}$ See Franz Brentano, The Origin of our Knowledge of Right and Wrong, ed. Oskar Kraus, trans. Roderick M. Chisholm and Elizabeth H. Schneewind, New York, 1969, p. 22; Roderick M. Chisholm, 'The Ethics of Requirement', American Philosophical Quarterly, i (1964).

${ }^{30}$ Chisholm, 147.

${ }^{31}$ See W. D. Ross, Foundations of Ethics, Oxford, 1939, pp. 52 ff.; Lemos, p. 12.

${ }^{32}$ It may be that both moral and aesthetic requirement can be analysed in terms of some concept of requirement simpliciter, but I shall not pursue this here.

${ }^{33}$ Compare W. D. Ross on 'direct' vs. 'incidental' prima facie duties in his The Right and the Good, Oxford, 1930, p. 46. 
lower left and an incongruous colour in the upper right. Then there will be an indirect moral requirement to do this, a requirement that conflicts with the aesthetic requirement not to do it.

Other instances of moral requirement are easily given. Being a beneficiary, it is plausible to contend, morally requires gratitude; harm morally requires reparation; misfortune morally requires compassion - the list is long and familiar. Consider compassion. I cited this earlier as a trait that most would agree is morally good. I think that this is because it is an attitude that most would see to be morally fitting to its object, and it is intrinsically good when something morally fitting occurs. If I witness suffering and evince a morally appropriate degree of compassion, that is a good thing intrinsically; and it is an intrinsic good that is also a moral good precisely because of the moral appropriateness or fittingness that is involved.

I venture to say (although this is not crucial to my purpose in this paper) that all moral goods are intrinsic goods that rest on moral fittingness in the manner just described. If promise-making morally requires promise-keeping, harm reparation, and so on, then it is not just intrinsically but morally good when what is required occurs. ${ }^{34}$ If this is so, then all those moral goods that consist in the possession or manifestation of morally good traits in particular will likewise be intrinsic goods that rest on moral fittingness. Compassion confirms this claim, as just noted. So does conscientiousness; it is morally fitting that one be sensitive to questions of right and wrong. So does courage; it is morally fitting that one display bravery in the face of danger. And this is precisely what distinguishes the moral from the nonmoral virtues. However admirable intelligence, wit, or aesthetic sensitivity may be, it is surely not the case that there is a moral requirement to display these traits (unless the requirement is indirect, as mentioned two paragraphs ago).

But now notice this. Even if there is no (direct) moral requirement to display any of the nonmoral virtues, there is nonetheless, as has been acknowledged, a requirement to admire them when they are displayed. What sort of a requirement is this? Surely the answer is: moral. It is morally fitting that one admire all virtues, whether or not the virtues themselves are moral. Likewise, it is morally fitting that one reprehend all vices, whether or not the vices themselves are moral. This is something that is often overlooked; one must not confuse the sort of fittingness (if any) that a virtue might itself involve with the sort of fittingness involved in the admiration of the virtue. Gauguin's

${ }^{34}$ In saying this, I am of course not saying that it is either intrinsically or morally good that, for example, the harm (that requires reparation) or the misfortune (that requires compassion) itself occurs. 
artistic talent involved a certain type of aesthetic sensitivity to his surroundings, an attitude which, it is plausible to say, was aesthetically appropriate to those surroundings. If we share this sensitivity, then we likewise display an aesthetically fitting attitude. But admiration of this sensitivity is one step removed from sharing it. It is an attitude that reveals a certain other type of sensitivity - a moral one - in the person who possesses it (a sensitivity which can be exhibited even when one does not share the aesthetic sensitivity that Gauguin displayed). Or consider what Slote says of Gauguin's single-mindedness: '[It] is ..., if anything, a morally unjustified motive or character trait, and any virtue we find in it, any admiration we feel for it, is predominately not of a moral kind' ${ }^{35}$ Again, while it can surely be agreed that the virtue in question (if it is such) is not a moral one and thus that we do not, or at least ought not to, take it to be a moral one and admire it as such, this does not imply that our admiration for it is not itself morally fitting. And it seems clear that the attitude is a morally fitting one (given the admirability of the trait in question). Someone who admires what is admirable and reprehends what is reprehensible is doing what is morally required of him (or her); his attitude is evidence of his moral rectitude.

There is thus a moral aspect even to those nonmoral traits that are admirable (and reprehensible): one is morally required to admire (and reprehend) them. (Indeed, this aspect is twofold, for someone who admires what is admirable and reprehends what is reprehensible displays an attitude that is not just morally fitting but is itself admirable. ${ }^{36}$ In saying this, I am not advocating a 'broadening' of morality, to the effect that virtues and vices that have traditionally been seen to be nonmoral should instead be seen to be moral. ${ }^{37}$ On the contrary, the distinction between those virtues and vices that are moral and those that are nonmoral remains. My point is simply that even nonmoral goods and evils morally require certain attitudes. I said at the beginning of this paper that this point has been inadequately appreciated; I mean, more precisely, that this is so in the context of the discussion of admirable immorality. ${ }^{38}$ Many have recognized or have come close to recognizing it in other contexts. For example, those (like G. E. Moore and W. D. Ross) who claim that there is a moral obligation to promote intrinsic goods and avoid intrinsic evils, even when such goods and

${ }_{35}$ Slote, p. 91.

${ }^{36}$ Compare Thomas Hurka, 'Virtue as Loving the Good', Social Philosophy, ix (1992), where the term 'virtue' is restricted to this trait.

${ }_{37}$ Wolf rejects this move at $433 \mathrm{f}$.

${ }^{38}$ There is some evidence that it has been recognized, but the evidence is at best inconclusive. See, e.g., Williams, p. 37 (but contrast p. 38); Wolf, 426 and 438 (but contrast $435 \mathrm{f}$.); McCarty. 
evils are not themselves moral goods and evils, clearly recognize the moral relevance of nonmoral goods and evils. Indeed, this is in many ways a mundane observation, and its being so serves, I believe, to defuse any threat to morality, as traditionally conceived, that might seem to be in the offing, as I shall now try to show.

\section{THE OVERRIDINGNESS THESIS}

It is not clear what is meant by the claim that moral considerations are always overriding. Perhaps one thesis that Slote and others have had in mind is this:

(OT1) All morally good traits are more admirable than any nonmorally good traits.

I think it is clear that the intermediate theses do not imply that (OT1) is false. After all, one can find single-mindedness in the pursuit of nonmoral goods admirable, or daring admirable, or culinary expertise admirable, while finding these things less admirable than compassion, courage, or conscientiousness. And this is so even if one believes these traits to bear some intrinsic connection with morally bad traits; indeed, such a connection may be thought to constitute a reason to embrace (OT1). Of course, if we find certain nonmoral traits (in some of their particular manifestations) more admirable than certain moral traits (in some of theirs), then we must reject (OT1); and, I believe (but shall not argue), we should do just this. Perhaps this is (part of) what Slote and others have intended. Nonetheless, it bears repeating that the intermediate theses themselves do not imply that (OT1) is false.

Whether or not one rejects (OT1), it should be clear by now how it can happen that an agent's action should manifest an admirable (or nonadmirable) trait and yet reflect ill (or well) on him or her. This is simply due to the perfectly familiar fact that one's actions can manifest a number of traits, whether moral or nonmoral, some admirable, others not. There is perhaps a sort of tension here, but no paradox lurks, and there is no reason to infer that morality is somehow under siege.

(OT1), however, is surely not the only thesis that someone who believes that moral considerations are always overriding might have in mind. Indeed, it does not fit talk of 'considerations' very well at all. Perhaps what some (including Slote) have intended is the following thesis, which, because it concerns choices, seems to have more to do with 'considerations':

(OT2) If ever one must choose between promoting a moral good and promoting a nonmoral good, one ought morally to choose the former.

If (OT1) is to be rejected, it is hard to see why (OT2) should be 
accepted. Indeed, it seems clear that (OT2) is false, and that its falsity is perfectly in keeping with morality as traditionally conceived. If, for example, one must choose between cultivating a small amount of compassion in someone and bringing about an immense amount of innocent pleasure, one ought morally, I believe, to choose the latter. ${ }^{39}$ More to the point here, however, is that, once again, the intermediate theses do not imply that (OT2) is false. As before, one can find singlemindedness in the pursuit of nonmoral goods, or daring, or culinary expertise morally worth promoting, while finding these things less worth promoting than compassion, courage, or conscientiousness.

It seems clear to me that neither of the two foregoing theses is what most people have in mind when they declare moral considerations overriding. For normally the discussion in this context concerns the justification of actions. This is certainly something that Slote and others have been concerned with. ${ }^{40}$ The idea seems to be that actions may be justified (or not) from a variety of points of view, both moral and nonmoral (e.g., prudential, legal, etc.). The overridingness thesis in question is the thesis that moral justification always takes precedence over nonmoral justification. That is:

(OT3) If ever one ought morally to do some act $A$ and ought nonmorally to do some incompatible act $B$, then one ought to do $\mathrm{A}$.

This is a puzzling thesis, for the final 'ought' is not characterized as being either moral or of a particular nonmoral variety. If what is intended by it is 'ought morally', then of course (OT3) is true, but only trivially so. If what is intended is 'ought prudentially (or legally, or ...)', then (OT3) would seem false (although there are of course some who would contend - implausibly, I would have thought - that morality always 'pays' and hence that one ought prudentially always to do what one ought morally to do).${ }^{41} \mathrm{I}$ think typically what is intended is that the final 'ought' is not to be construed as of any particular variety but as an 'ought full stop' - a kind of all-encompassing 'ought' that transcends the various particular points of view. What is puzzling about this is that such a transcendent 'ought' would appear to presuppose that the various points of view, both moral and nonmoral, are in some manner commensurate with one another, so that the moral 'ought' can be properly deemed weightier than the rest. I find myself unable to grasp this alleged commensurability. ${ }^{42}$

${ }^{39}$ Compare Hurka, sect. 4; contrast Ross, Foundations, p. 275.

${ }^{40}$ See Slote, pp. 84 and 88. Compare Williams, p. 18; Philippa Foot, Virtues and Vices, Berkeley, 1978, p. 185; Wolf, 434.

${ }^{41}$ The view that morality always pays can be traced, in one form or another, back through Butler and Hobbes to Plato, if not beyond.

${ }^{42}$ Note that this is not just a matter of plural goods or values being commensurable, 
It seems to me, then, that (OT3) is to be rejected, but not because this contrary thesis is to be accepted:

(OT3') Sometimes, when one ought morally to do some act A but ought nonmorally to do some incompatible act $B$, one ought to do $\mathrm{B}$.

This thesis, too, strikes me as incoherent. But perhaps my failure to find (OT3) and (OT3') coherent is just a deficiency in me; perhaps they are perfectly coherent after all. There are certainly many people who claim that morality implies that (OT3) is true (and hence that (OT3') is false), and this view - which may, I think, be properly called a (and perhaps even the) traditional view of morality - obviously presupposes the coherence of (OT3) and (OT3'). But even if these theses are coherent, I cannot see any connection between them and the intermediate theses; in particular, I can see no reason to think that (IT1) implies (OT3'), as Slote seems to allege. For (IT1) concerns the admirability of certain personal traits, whereas (OT3') concerns the justifiability of actions. The former has to do with agent-evaluation, the latter with act-evaluation, ${ }^{43}$ and even if these two types of evaluation have some interrelation, this alleged implication surely fails. For, regardless of whether or not (OT3) and (OT3') are in fact coherent, it is surely perfectly consistent to adopt the view to which I am inclined, namely, that certain nonmoral traits (perhaps even certain traits that have some intrinsic connection with immorality) are admirable (perhaps even more admirable than certain moral traits), and yet both (OT3) and (OT3') are to be rejected because they are incoherent.

In sum, given the fact that the intermediate theses fail to imply that any of the overridingness theses identified above are false, and the fact that even those nonmoral goods (and evils) that are admirable (and reprehensible) have the moral aspect identified above, there would appear to be little reason to think that the phenomena of admirable immorality and nonadmirable morality - if, indeed, they actually occur - pose any sort of threat to morality as it is traditionally conceived. ${ }^{44}$

m_zimme2@hamlet.uncg.edu

as discussed in ch. 6 of Michael Stocker, Plural and Conflicting Values, Oxford, 1990. It is a matter of plural types of goods or values being commensurable. (Stocker would rather talk of 'comparability' than of 'commensurability' in this context. I shall not discuss this issue here.)

43 Ibid., p. 39.

${ }^{4}$ My thanks to Erik Carlson and to the Editor for comments on an earlier draft. 